\title{
Daily heterotrophic respiration model considering the diurnal temperature variability in the soil
}

\author{
J. M. Chen, ${ }^{1}$ S. E. Huang, ${ }^{1,2}$ W. Ju, ${ }^{1}$ D. Gaumont-Guay, ${ }^{3}$ and T. A. Black ${ }^{3}$ \\ Received 26 July 2008; revised 4 November 2008; accepted 3 December 2008; published 20 March 2009.
}

[1] In daily, monthly, and annual respiration models for regional and global applications, the diurnal variation of temperature is generally ignored. As the effect of temperature on respiration is nonlinear, this ignorance may cause considerable errors in respiration estimation, but these errors have not yet been systematically investigated. This is in fact a central issue in temporal scaling of ecosystem models which are often applied in time steps equal to or larger than a day. In this study, we develop an integrated daily heterotrophic respiration model, and demonstrate first theoretically the importance of considering the diurnal amplitude of soil temperature and the vertical soil carbon distribution pattern in daily respiration estimation using the daily mean temperature. Measurements of soil respiration with roots exclusion made in a mature black spruce site in Saskatchewan, Canada, in July-September 2004 are used to validate the model. Daily heterotrophic respiration rates were underestimated by up to $15 \%$, with a mean value of $4.5 \%$, when only the mean daily temperature was used. This underestimation occurred under the conditions that the diurnal temperature amplitude in the forest was less than $12^{\circ} \mathrm{C}$ and the vertical distribution of organic carbon in the top $15-30 \mathrm{~cm}$ was uniform. Based on the integrated daily model, this underestimation at the same site would be $38 \%$ if the amplitude increases to $20^{\circ} \mathrm{C}$, and in soils with steep vertical carbon distributions with a $20^{\circ} \mathrm{C}$ diurnal amplitude, it can increase to $44 \%$. The magnitude of this underestimation is theoretically proportional to $\left[\ln \left(Q_{10}\right)\right]^{2}$. During the experimental period, the value of $Q_{10}$ for heterotrophic respiration was found to be 4.0-4.5. If $Q_{10}=$ 2.0, this underestimation is reduced to about $10 \%$ at a diurnal temperature amplitude of $20^{\circ} \mathrm{C}$.

Citation: Chen, J. M., S. E. Huang, W. Ju, D. Gaumont-Guay, and T. A. Black (2009), Daily heterotrophic respiration model considering the diurnal temperature variability in the soil, J. Geophys. Res., 114, G01022, doi:10.1029/2008JG000834.

\section{Introduction}

[2] Soil respiration consists of two functionally different components: rhizosphere (roots and mycorrhizae) respiration and heterotrophic respiration from free-living microbes. It provides the main carbon efflux from ecosystems to the atmosphere and is therefore an important component of the global carbon balance [Schimel, 1995]. On average, global heterotrophic respiration emits $68-76.5 \mathrm{Pg} \mathrm{Cy}^{-1}$ to the atmosphere [Raich and Schlesinger, 1992; Raich and Potter, 1995]. Biologists have long used $Q_{10}$ to describe the dependence of biological processes on temperature, a concept originating in the nineteenth century physicalchemistry models of Arrhenius [1889] and Van't Hoff [1898]. The $Q_{10}$ function assumes an exponential relation-

\footnotetext{
${ }^{1}$ Department of Geography, University of Toronto, Toronto, Ontario, Canada.

${ }^{2}$ Meteorological Research Institute of Jiangxi Province, Nanchang, China.

${ }^{3}$ Faculty of Agricultural Science, University of British Columbia, Vancouver, British Columbia, Canada.
}

Copyright 2009 by the American Geophysical Union. 0148-0227/09/2008JG000834 ship between respiration and temperature. In recent years, some studies have sought to establish relationships of soil respiration with soil moisture and temperature [Lloyd and Taylor, 1994; Thierron and Laudelout, 1996; Davidson et al., 1998; Gulledge and Schimel, 2000; Xu and Qi, 2001a]. There is increasing evidence that $Q_{10}$ of soil respiration is not seasonally constant and tends to decrease with increasing temperature and decreasing soil moisture [Rayment and Jarvis, 2000; Davidson et al., 2000; Xu and Qi, 2001b; Drewitt et al., 2002; Luo et al., 2001; Qi et al., 2002; Janssens and Pilegaard, 2003]. Despite these and other limitations, a simple exponential function based on a fixed $Q_{10}$ value of about 2.0 has gained wide acceptance in modeling regional and global ecosystem respiration and its responses to climate change [Ryan, 1991; Aber and Federer, 1992; Melillo et al., 1993; Schimel et al., 1997; Cramer et al., 1999; Tjoelker et al., 2008].

[3] Janssens et al. [2003] suggested that if the objective of a model is to simulate the total annual soil respiration, an annual model parameterization suffices. However, if the simulation period is days or weeks, as in the case when soil respiration is affected by synoptic weather events, a shortterm parameterization is required. The need for these 


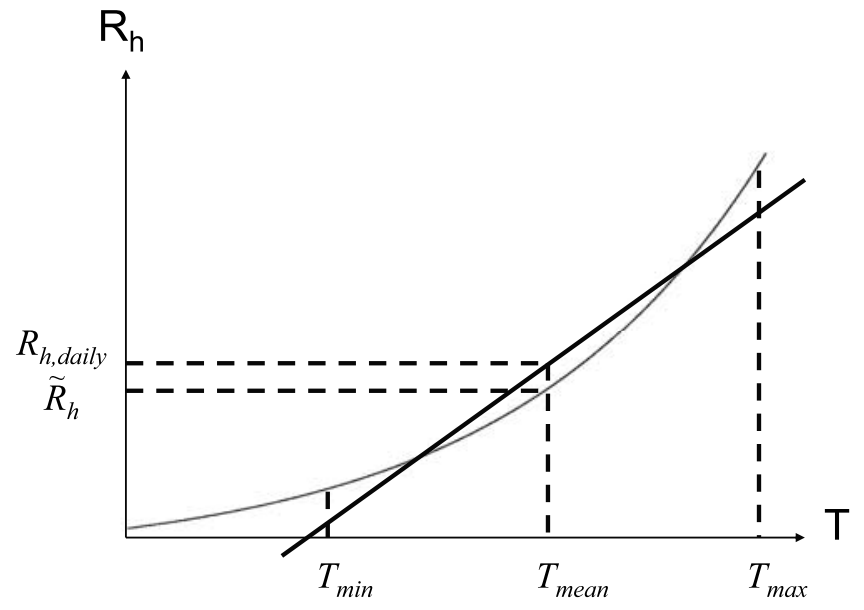

Figure 1. A schematic showing the difference between diurnally integrated daily heterotrophic respiration $\left(R_{h, \text { daily }}\right)$ and the approximate daily heterotrophic respiration $\left(R_{h}\right)$ obtained using the daily mean temperature. $R_{h, \text { daily }}$ is the correct value determined by making the area under the straight line the same as that under the curve between $\mathrm{T}_{\min }$ and $\mathrm{T}_{\max } . R_{h, \text { daily }}$ and $\tilde{R}_{h}$ are different because of the nonlinear relationship between heterotrophic respiration and temperature.

different parameterizations for different time steps may be due to the nonlinear response of respiration to temperature. Many models operate at monthly or seasonal or annual time steps [Parton et al., 1987; Parton and Scurlock, 1993; Peng et al., 1998; Cramer et al., 1999; Irvine and Law, 2002; Chen et al., 2003; Rodeghiero and Cescatti, 2005], and even if some models use daily time steps, they only consider variations from day to day [Russell and Voroney, 1998; Lee et al., 2002] or half-daily [Braswell et al., 2005]. So far, there have been no published works on daily models considering the effects of the diurnal temperature variation on daily respiration estimation, although there have been numerous subdaily measurements. As the response of respiration to temperature is not linear, the diurnal temperature amplitude would have significant influence on daily respiration estimation using daily mean temperature. Figure 1 shows that the daily heterotrophic respiration would be significantly underestimated using the mean daily temperature in comparison with the correct value determined through daily integration, and this underestimation would increase with increasing diurnal temperature amplitude. Considering this nonlinear effect would, therefore, be an important temporal scaling step for daily, monthly and annual respiration models, which so far has been ignored.

[4] In this paper, we focus on the development of a model simulating heterotrophic respiration at daily time steps with a correction for the effect of the nonlinear response of respiration to diurnal temperature variation. The objectives of this paper are: (1) to derive an analytical solution to the daily integral of heterotrophic respiration for the purpose of correcting the bias of simple $Q_{10}$ models based on daily mean air temperature; (2) to validate this integrated daily model using field measurements and to demonstrate the ability of this model in capturing the effect of diurnal temperature variation at daily time steps; (3) to investigate the importance of key parameters, including the diurnal temperature amplitude and the organic carbon density profile in the soil, in estimating heterotrophic respiration at daily time steps.

\section{Daily Model Description}

\subsection{Simple Daily Model of Heterotrophic Respiration}

[5] In this study, we select the $Q_{10}$ function [Van't Hoff, $1898]$ to describe the sensitivity of heterotrophic respiration to temperature as follows:

$$
R_{h}=R_{10} f(\bar{T})=R_{10} Q_{10}^{\frac{\bar{T}-10}{10}}
$$

where $R_{h}$ is the heterotrophic respiration flux at the mean soil temperature $\bar{T}$ over an time interval, $R_{10}$ is the rate of heterotrophic respiration at a soil temperature of $10^{\circ} \mathrm{C}$, and $Q_{10}$ is the temperature sensitivity of heterotrophic respiration and is an empirical parameter, representing the relative increase of the respiratory flux as temperature increases by $10^{\circ} \mathrm{C}$. Equation (1) is often called 'the $Q_{10}$ model', which is most commonly reported in the literature. As the temperature sensitivity of heterotrophic respiration generally decreases with increasing temperature, the value of $Q_{10}$ would change with temperature, making it seasonally dependent. Although alternatives to $Q_{10}$ have been proposed by considering the increase in activation energy cost with temperature [Lloyd and Taylor, 1994], $Q_{10}$ is continuously used in many recent studies [Tjoelker et al., 2008; Wythers et al., 2005] for its effectiveness in capturing the thermal acclimation effect on respiration.

[6] Heterotrophic respiration is also influenced by total soil carbon, litter quality, and moisture. In order to develop a simple and effective diurnal scaling algorithm, we have chosen to consider the soil carbon vertical profile as an additional parameter to temperature, while the effects of other parameters will be evaluated through their association with existing model parameters (see section 5). Normally, the soil organic carbon content decreases with depth from the soil surface [Jobbagy and Jackson, 2000]. The total soil organic carbon in the whole soil profile is expressed as:

$$
w_{t}=\int_{0}^{z_{d}} \rho_{b}(z) \cdot w_{g}(z) d z=\int_{0}^{z_{d}} c_{w}(z) d z
$$

where $w_{t}$ is the total organic carbon per unit surface area $\left(\mathrm{kg} \mathrm{m}^{-2}\right), \rho_{b}(z)$ is the soil bulk density $\left(\mathrm{kg} \mathrm{m}^{-3}\right)$ at depth $z$, $w_{g}(z)$ is the weighted fraction of soil organic carbon $\left(\mathrm{kg} \mathrm{kg}^{-1}\right), c_{w}(z)$ is the volumetric organic carbon content $\left(\mathrm{kg} \mathrm{m}^{-3}\right)$, and $z_{d}(m)$ is the lower boundary of the carboncontaining soil depth. The profile of soil organic carbon with depth can be defined as:

$$
w(z)=\frac{c_{w}(z)}{w_{t}}
$$

where $w(z)$ is in $\mathrm{m}^{-1}$ and can be regarded as a weighting function for contributions of soil carbon at various depths. Daily heterotrophic respiration is often calculated using daily mean soil temperature $(\bar{T})$. Using equation (1) to 


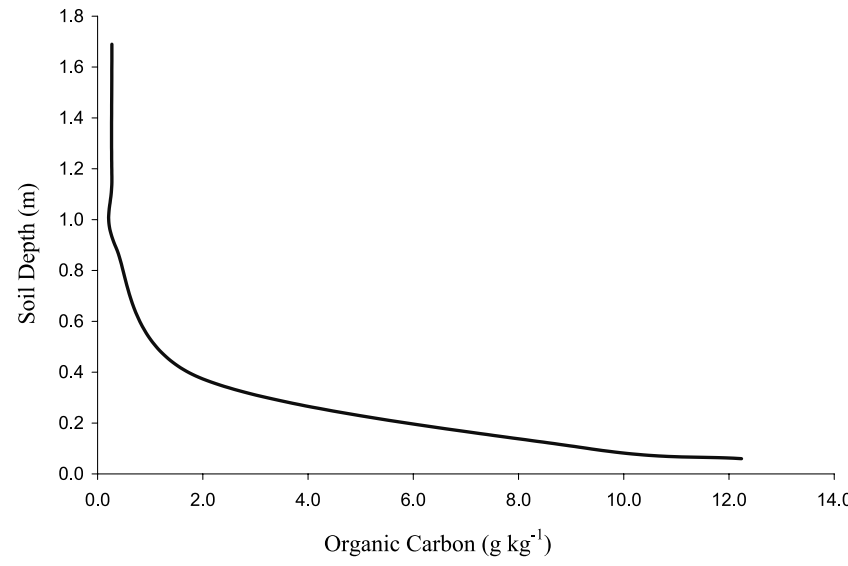

Figure 2. Organic carbon content changes with soil depth at the study site (old black spruce [Grant et al., 2005]).

represent the hourly heterotrophic respiration and distributing it with depth using $w(z)$, we can integrate the hourly values with respect to depth and time to obtain the daily heterotrophic respiration $\left(\tilde{R}_{h}\right)$ :

$$
\tilde{R}_{h}=\int_{0}^{24} \int_{0}^{z_{d}} w(z) R_{s} d z d t=\int_{0}^{24} \int_{0}^{z_{d}} w(z) R_{10} Q_{10}^{\frac{\bar{T}-10}{10}} d z d t=24 R_{10} Q_{10}^{\frac{\bar{T}}{10}-1}
$$

where $R_{10}$ represents the total hourly respiration rate at $10^{\circ} \mathrm{C}$ after integrating $w(z)$ with respect to $z$, which is time invariant if the total soil carbon does not change with time. We refer to equation (4) as a simple daily respiration model. Its simple form is derived under the assumption that the variations of soil temperature $(\bar{T})$ with depth and time can be ignored. It is therefore considered as an approximation.

\subsection{Integrated Daily Model of Heterotrophic Respiration}

\subsubsection{Daily Heterotrophic Respiration}

[7] In order to model the diurnal variation of heterotrophic respiration caused by the diurnal variation in soil temperature at different depths, we rewrite equation (4) as follows:

$$
R_{h, \text { daily }}=\int_{0}^{24} \int_{0}^{z_{d}} w(z) R_{10} Q_{10}^{\frac{T_{s}(z, t)-10}{10}} d z d t
$$

where $R_{h \text {,daily }}$ is the daily total heterotrophic respiration calculated with diurnally variable soil temperature. Equation (5) is also referred to as an integrated daily respiration model, where $T_{s}(z, t)$ is the soil temperature at time $(t)$ and depth $(z)$. Here, we treat $R_{10}$ and $Q_{10}$ to be same as those in equation (4).

\subsubsection{Model for Soil Temperature}

[8] With the assumption that physical properties of soil are constant with depth, the equation of soil heat conduction can be expressed as [Monteith and Unsworth, 1990]:

$$
\frac{\partial T_{s}(z, t)}{\partial}=\kappa^{\prime} \frac{\partial^{2} T_{s}(z, t)}{\partial z^{2}}
$$

where $\kappa^{\prime}$ is the thermal diffusivity of soil, and $T_{s}(z, t)$ is the temperature at depth $\mathrm{z}$ and time $t$. The solution of equation (6) satisfying the boundary condition which describes a harmonic oscillation of temperature at depth $\mathrm{z}$ is:

$$
T_{s}(z, t)=\bar{T}+A(z) \sin (\omega t-z / D)
$$

where $\bar{T}$ is the mean soil temperature at the surface, $\omega=2 \pi / 24$ $\left(\mathrm{h}^{-1}\right)$ is the angular frequency of the oscillation for daily cycles, $A(z)=A(0) \exp (-z / D)$ is the amplitude of soil temperature at depth $z, A(0)=A \cos \phi$ is the amplitude at the surface, $A$ is the air temperature amplitude, $\phi=\tan ^{-1}(2 \pi \tau / p)$ is a phase lag, $p$ is the period of the temperature oscillation, and $D=\left(2 \kappa^{\prime} / \omega\right)^{0.5}$ is the damping depth. For $p=24 \mathrm{~h}, \phi$ is small and $A(0) \approx A$ since the time lag $(\tau)$ of temperature oscillation from the air temperature is close to zero at the soil surface. So we can present $A(z)$ as follows:

$$
A(z) \approx A \exp (-z / D)
$$

Combining equation (7) with equation (5), the total daily heterotrophic respiration with explicit consideration of the temperature variations with time and depth in the soil can be written as:

$$
\begin{aligned}
R_{h, \text { daily }} & =\int_{0}^{z_{d}} \int_{0}^{24} w(z) R_{10} Q_{10}^{\frac{T_{s}(z, t)-10}{10}} d z d t \\
& =\int_{0}^{z_{d}} \int_{0}^{24} w(z) R_{10} Q_{10}^{\frac{\bar{T}+A(z) \sin (\omega t-z / D)-10}{10}} d z d t \\
& =\int_{0}^{z_{d}} R_{10} w(z) \int_{0}^{24} Q_{10}^{\frac{T}{T+A \exp (-z / D) \sin (\omega t-z / D)-10}} d z d t \\
& =R_{10} Q_{10}^{\frac{\bar{T}}{10}-1} \int_{0}^{z_{d}} w(z) \int_{0}^{24} Q_{10}^{\frac{A \exp (-z / D) \sin (\omega t-z / D)}{10}} d z d t
\end{aligned}
$$

\subsubsection{Variation of Soil Organic Carbon With Depth}

[9] In this study, the contribution of soil at depth $z$ to the total heterotrophic respiration is mainly controlled by the organic carbon amount $c_{w}(z)$. Based on Grant et al. [2005], who provided observed data at three boreal forest sites in Canada, the variation of soil organic carbon with depth can be generally described using an exponential function (Figure 2):

$$
c_{w}(z)=c_{0} e^{-k z}
$$

where $c_{0}$ is the volume organic carbon content at soil surface, a constant for a given site, $k$ is a constant determining the decay rate of organic carbon content with soil depth. Substituting equation (10) into equation (3), the weight function can be rewritten as:

$$
w(z)=\frac{c_{w}(z)}{w_{t}}=\frac{c_{0}}{w_{t}} \cdot e^{-k z}
$$


We can also calculate the total organic carbon through the soil depth as

$$
w_{t}=\int_{0}^{z_{d}} c_{w}(z) d z=\int_{0}^{z_{d}} c_{0} e^{-k z} d z=\frac{c_{0}}{k}\left(1-e^{-k z_{d}}\right)
$$

This simple vertical weighting scheme is derived under the assumption that the vertical distribution of soil carbon follows a single decay rate $k$.

\subsubsection{Integrated Daily Model of Heterotrophic} Respiration With Consideration of Diurnal Temperature Variation

[10] After using $\omega=(2 \pi / 24)$ in equation (9) and transforming the variables, we obtain the following integrated result for daily heterotrophic respiration:

$$
\begin{aligned}
R_{h, d a i l y} & =R_{10} Q_{10}^{\frac{\bar{T}}{10}-1} \int_{0}^{z_{d}} w(z) \int_{0}^{24} Q_{10}^{\frac{\operatorname{Aexp}(-z / D) \sin \left(\frac{2 \pi}{24}-z / D\right)}{10}} d z d t \\
& =24 R_{10} Q_{10}^{\frac{T}{T-1}-1} \int_{0}^{z_{d}} w(z) \int_{0}^{1} Q_{10}^{\frac{A \exp (-z / D) \sin (2 \pi x-z / D)}{10}} d z d x \\
& =24 R_{10} Q_{10}^{\frac{\bar{T}}{10}-1} \int_{0}^{z_{d}} w(z) \int_{0}^{1} e^{\frac{\ln Q_{10}}{10} A \sin (2 \pi x-z / D) \exp (-z / D)} d z d x
\end{aligned}
$$

After making the third order Taylor series expansion of the exponential function in equation (13), it can be expressed as:

$$
\begin{aligned}
R_{h, \text { daily }}= & 24 R_{10} Q_{10}^{\frac{\bar{T}}{T_{10}}-1} \int_{0}^{z_{d}} w(z) d z \int_{0}^{1} \\
& \cdot\left[1+\frac{\ln Q_{10}}{10} A \sin (2 \pi x-z / D) \exp (-z / D)\right. \\
& \left.+\frac{\left(\ln Q_{10}\right)^{2}}{200} A^{2} \sin ^{2}(2 \pi x-z / D) \exp ^{2}(-z / D)\right] d x \\
= & 24 R_{10} Q_{10}^{\frac{T}{1}}-1 \int_{0}^{z_{d}}\left(w(z)+\frac{\left(\ln Q_{10}\right)^{2}}{400} A^{2} w(z) \exp (-2 z / D)\right) \\
& \cdot d z
\end{aligned}
$$

Note that $\int^{1} \sin (2 \pi x-z / D) d x=0$ and $\int^{1} \sin ^{2}(2 \pi x-z / D) d x=$ 1. Based 0 on the single decay rate ${ }^{0}$ assumption for soil carbon, i.e., equations (11) and (4), equation (14) can be written as:

$$
\begin{aligned}
R_{h, \text { daily }}= & 24 R_{10} Q_{10}^{\frac{\bar{T}}{T_{0}}-1}+24 R_{10} Q_{10}^{\frac{\bar{T}}{10}-1} \int_{0}^{z_{d}} \frac{\left(\ln Q_{10}\right)^{2}}{400} A^{2} w(z) \\
& \cdot \exp (-2 z / D) d z \\
= & \tilde{R}_{h}\left(1+\frac{C_{0} A^{2}\left(\ln Q_{10}\right)^{2}}{400 w_{t}(k+2 / D)}\left(1-e^{-(k+2 / D) z_{d}}\right)\right)
\end{aligned}
$$

It is noted that $A$ in equation (15) in its final form is the diurnal temperature amplitude at the soil surface, not at the mean soil depth. In this way, the temperature variations in all depths are considered in this integrated result. As $A$ is very close to the diurnal amplitude of air temperature near the surface, it can be determined using the air temperature as a close approximation.

[11] Equation (15) is an integrated daily model for heterotrophic respiration with consideration of the diurnal temperature variability at various depths and the organic matter profile in the soil. The second term in the brackets results from the nonlinear effect of temperature on heterotrophic respiration, i.e., the relative difference between $R_{h, \text { daily }}$ and $\tilde{R}_{h}$ shown in Figure 1 .

\subsubsection{Special Cases of Integrated Daily Heterotrophic} Respiration Models

\subsubsection{Uniform Soil Carbon Profile}

[12] Based on measurements from our experimental site (see section 3 and Table 1), the soil has roughly homogeneous organic layer of $15-30 \mathrm{~cm}$ thickness above the mineral soil. As this organic layer, originating mostly from litter falls and fine-root and moss turnovers, is the main source of heterotrophic respiration, the decay rate of organic carbon with soil depth $(k)$ from the top of this organic layer is set to zero in analyzing our experimental data, i.e., setting $w_{t}=c_{0}\left(z_{d}-z_{0}\right)$ (equation (13)) and $k=0$ in equation (15), which is then simplified to:

$$
R_{h, d a i l y}=\tilde{R}_{h}\left(1+\frac{D A^{2}\left(\ln Q_{10}\right)^{2}}{800 z_{d}}\left(1-e^{-2 Z_{d} / D}\right)\right)
$$

Assigning $\Delta R_{h}=\frac{D A^{2} \ln ^{2} Q_{10}}{800 z_{d}}\left(1-e^{-2 Z_{d} / D}\right)$, equation (16) can be rewritten as:

$$
R_{h, \text { daily }}=\tilde{R}_{h}\left(1+\Delta R_{h}\right) \text { or } R_{h, \text { daily }} / \tilde{R}_{h}=\left(1+\Delta R_{h}\right)
$$

where $\Delta R_{h}$ is a term correcting for the bias of daily heterotrophic respiration estimation without considering the diurnal soil temperature variations. This correction is proportional to the square of the diurnal temperature amplitude. In our research, we regard $R_{h, \text { daily }}$ as the correct daily heterotrophic respiration (calculated by the integrated daily model given in equation (15)), and $\tilde{R}_{h}$ is an approximation (equation (4)) to be corrected using the correction term. Thus, $\tilde{R}_{h}$ reflects the effects of mean daily temperature, and $R_{h, \text { daily }}$ includes the effects of both average daily temperature and diurnal temperature amplitude.

\subsubsection{Variable Soil Carbon Profiles at Different Depths}

[13] For cases, where the soil organic carbon content profile cannot be well described by a single decay rate $k$, such as the case, where a litter/organic layer overlaying the mineral soil, or the total soil column has two or three layers with different carbon decay rates, the following equation can be used to estimate the nonlinear effect:

$$
\Delta R_{h}=\frac{A^{2}\left(\ln Q_{10}\right)^{2}}{400} \sum_{i=1}^{n} w_{i} k_{i} \frac{e^{-z_{i-1}\left(k_{i-1}+2 / D_{i-1}\right)}-e^{-z_{i}\left(k_{i}+2 / D_{i}\right)}}{\left(k_{i}+2 / D_{i}\right)\left(1-e^{-k_{i} \Delta z_{i}}\right)}
$$

where $k_{i}$ is the decay rate of the $i^{\text {th }}$ layer of soil, $w_{i}$ is the weight of carbon in soil layer $i$ to the total soil carbon, $D_{i}$ is the thermal damping depth for soil layer $i, \Delta z_{i}$ is the 
Table 1. Physical and Biological Properties of the Soil at the Old Black Spruce Site ${ }^{\mathrm{a}}$

\begin{tabular}{|c|c|c|c|c|c|c|c|c|c|}
\hline $\begin{array}{l}\text { Depth } \\
(\mathrm{m})\end{array}$ & $\begin{array}{c}\text { Bulk Density } \\
\left(\mathrm{Mg} \mathrm{m}^{-3}\right)\end{array}$ & $\begin{array}{l}\theta_{-0.03 \mathrm{Mpa}} \\
\left(\mathrm{m}^{3} \mathrm{~m}^{-3}\right)\end{array}$ & $\begin{array}{l}\theta_{-1.5 \mathrm{Mpa}} \\
\left(\mathrm{m}^{3} \mathrm{~m}^{-3}\right)\end{array}$ & $\begin{array}{c}\text { Sand } \\
\left(\mathrm{g} \mathrm{kg}^{-1}\right)\end{array}$ & $\begin{array}{c}\text { Silt } \\
\left(\mathrm{k} \mathrm{kg}^{-1}\right) \\
\end{array}$ & $\begin{array}{c}\text { Organic Carbon } \\
\left(\mathrm{g} \mathrm{kg}^{-1}\right)\end{array}$ & $\mathrm{PH}$ & $\begin{array}{c}\text { Organic Nitrogen } \\
\left(\mathrm{mg} \mathrm{kg}^{-1}\right)\end{array}$ & $\begin{array}{c}\text { Organic Phosphate } \\
\left(\mathrm{mg} \mathrm{kg}^{-1}\right)\end{array}$ \\
\hline 0.01 & 0.10 & 0.40 & 0.20 & 0 & 0 & 434 & 3.4 & 8162 & 900 \\
\hline 0.05 & 0.10 & 0.40 & 0.20 & 0 & 0 & 434 & 3.4 & 8162 & 900 \\
\hline 0.15 & 0.10 & 0.40 & 0.20 & 0 & 0 & 434 & 3.4 & 8162 & 900 \\
\hline 0.30 & 0.10 & 0.40 & 0.20 & 0 & 0 & 434 & 3.4 & 8162 & 900 \\
\hline 0.47 & 1.52 & 0.213 & 0.049 & 728 & 214 & 9.8 & 4.3 & 423 & 53 \\
\hline 0.72 & 1.66 & 0.183 & 0.05 & 646 & 287 & 3.6 & 4.9 & 215 & 27 \\
\hline 0.96 & 1.66 & 0.022 & 0.012 & 960 & 19 & 1.0 & 5.8 & 52 & 7 \\
\hline 1.20 & 1.66 & 0.034 & 0.013 & 949 & 30 & 0.5 & 6.6 & 52 & 7 \\
\hline
\end{tabular}

${ }^{\mathrm{a}}$ Abbreviations are as follows: $\theta_{-0.03 \mathrm{Mpa}}$, field capacity; $\theta_{-1.5 \mathrm{Mpa}}$, wilting point. Reference data from Grant et al. [2001].

thickness of the $i^{\text {th }}$ soil layer, and $z_{i}$ is the lower boundary (depth) of the $i^{\text {th }}$ layer. As there is no layer 0 , the initial values of $k$ and $z$ are: $k_{0}=0$ and $z_{0}=0$. Equation (18) is derived similarly to equation (15), allowing the thermal damping depth to vary vertically to consider different materials and soil moisture contents in different soil layers. It will be used for parameter sensitivity analysis shown in section 5 .

\section{Experimental Data and Model Parameterization}

\subsection{Site Description and Physical and Biological Properties}

[14] This study makes use of experimental data collected in a black spruce (P. mariana) stand (125 years old in 2004) located at the southern edge of the boreal forest in central Saskatchewan, Canada $\left(54.0^{\circ} \mathrm{N}, 105.1^{\circ} \mathrm{W}\right)$, which is often called the South Old Black Spruce Site for the Boreal Ecosystem-Atmosphere Study (BOREAS). The forest floor is covered by mostly (70\%) feather mosses (Hylocomium splendens, Pleurozium schreberi) in wetter areas and by patches Sphagnum moss (Sphagnum spp.) and lichen (Cladina spp.) in drier area. Beneath the moss layer is an approximately $20-\mathrm{cm}$ organic layer (including $\mathrm{O}$ and $\mathrm{P}$ horizons) overlying a waterlogged sandy clay (including $\mathrm{A}, \mathrm{B}$ and $\mathrm{C}$ horizons). The drainage at the site is poor. Mean fine-root biomass $(<2 \mathrm{~mm})$ to a depth of $40 \mathrm{~cm}$ is $3.3 \pm$ $1.0 \mathrm{Mg}$ dry matter ha ${ }^{-1}$ (average for 2003-2004) [Kalyn and Van Rees, 2006]. The physical and biological properties of this site [Grant et al., 2001] are shown in Table 1. The 30 -year mean annual air temperature and precipitation measured at a climate station located $80 \mathrm{~km}$ away (19341990, Waskesiu Lake, $53.6^{\circ} \mathrm{N}, 106.1^{\circ} \mathrm{W}$ ) are $0.3^{\circ} \mathrm{C}$ and $456 \mathrm{~mm}$, respectively. Boreal forests globally occupy about $20 \mathrm{M} \mathrm{km}^{2}$ of the land surface, and black spruce is the most dominant boreal species [Hall et al., 2004]. The results from this study would therefore be significant for the global carbon cycle estimation. The thick organic layer on top of the mineral soil found at our study site is typical of black spruce forests. Because of the thermal insulation effect of this layer, the diurnal temperature amplitude in the soil under the forest cover is relatively small compared with other forest types, and the magnitude of the temporal scaling effect on heterotrophic respiration estimation found in our study would therefore represent the lower bound of this effect globally.

\subsection{Experimental Data for Model Validation}

[15] The half-hourly measurements of heterotrophic respiration through root-exclusion experiments were conducted in 2004 [Gaumont-Guay et al., 2008]. Two pairs of control and root-exclusion plots $(2 \mathrm{~m} \times 2 \mathrm{~m})$ were installed in the fall of 2001. In each square plot, trenches were dug at the edges to a depth of $75 \mathrm{~cm}$ to exclude all live tree roots, and the trench walls were covered with four sheets of polyethylene film (100 $\mu \mathrm{m}$ thick) to prevent the penetration of new roots. The trenches were then backfilled with the excavated soil. Two additional pairs of plots were installed in September 2003 following the same procedure, bringing the number of replicates per treatment to four.

[16] Continuous half-hourly measurements of soil $\mathrm{CO}_{2}$ efflux were conducted during the growing season of 2004 , although only the data acquired in July-September 2004 are used in this study to minimize the possible pulse of dead root decomposition which may last several months after trenching [Lee et al., 2003]. Gaumont-Guay et al. [2008] found that the residual dead root decomposition lingered for more than a year, and therefore the heterotrophic respiration data from the two pairs of plots installed in 2003 would contain a small fraction from dead root decomposition (not quantified), while measurements in the other two pairs installed in 2001 would be free from this effect. The contribution of the remaining slow root decomposition to the measured heterotrophic respiration could be partly offset by the removal of rhizomicrobial respiration by heterotrophs associated with the cut roots. Live root rhizomicrobial respiration was found to contribute $32 \%$ to the total root respiration of a meadow fescue [Johansson, 1992]. Measurements were made with a nonsteady state automated chamber system. The chambers consisted of a domedshaped transparent lid $(52.5 \mathrm{~cm}$ diameter $\times 20.5 \mathrm{~cm}$ height $)$ inserted between 3 and $4 \mathrm{~cm}$ below the live-moss layer. Opening and closing of the lid was done with a pneumatic cylinder assembly (Model BFT-173-DB, Bimba Manufacturing Company, Machesney Park, IL, USA) connected to an air compressor (Model CPFAC2600P, Porter Cable, Jackson, TN, USA). About $92 \%$ of the time, the lid was open to allow rain and litter to fall into the collar area. The system measured the increase of $\mathrm{CO}_{2}$ concentration in the chamber headspace over a 2.5 -min interval sequentially for the eight chambers, allowing all chambers to be measured once every half-hour. When a chamber was selected, the air was circulated between the chamber and a closed-path infrared gas analyzer (IRGA, Model LI-6262, LI-COR Inc., Lincoln, NE, USA) with an AC linear pump (Model 
Table 2. Parameters at the Old Black Spruce Site for Heterotrophic Respiration Calculation

\begin{tabular}{|c|c|c|c|}
\hline Symbol & Unit & Description & Value \\
\hline \multicolumn{4}{|c|}{ General } \\
\hline$\omega$ & $\mathrm{h}^{-1}$ & Angular frequency & $2 \pi / 24$ \\
\hline$\kappa^{\prime}$ & $10^{-6} \mathrm{~m}^{2} \mathrm{~s}^{-1}$ & Thermal diffusivity & 0.13 \\
\hline$D$ & $\mathrm{~cm}$ & Damping depth & 5.98 \\
\hline$z_{d}$ & $\mathrm{~cm}$ & Soil depth contributing to heterotrophic respiration & 15 \\
\hline$c_{0}$ & $\mathrm{~kg} \mathrm{~m}^{-3}$ & Organic carbon at the soil surface & 43.4 \\
\hline$k$ & $\mathrm{~cm}^{-1}$ & Decay rate of organic $C$ with depth & 0 \\
\hline \multicolumn{4}{|c|}{ Respiration } \\
\hline$Q_{10}$ & unitless & Temperature sensitivity of heterotrophic respiration & $4.0-4.5$ \\
\hline$R_{10}$ & $\mathrm{gC} \mathrm{m}{ }^{-2} \mathrm{~d}^{-1}$ & Heterotrophic respiration at soil temperature of $10^{\circ} \mathrm{C}$ & $1.66-1.96$ \\
\hline
\end{tabular}

SPP-15EBS-101, Gast Manufacturing, Benton Harbor, MI, USA). A small fan ensured the air in the chamber was well mixed. The IRGA was located in a thermally controlled housing with a constant temperature at $38^{\circ} \mathrm{C}$. The IRGA was calibrated daily using $\mathrm{CO}_{2}$-free nitrogen gas (offset calibration) and a dry air gas of known $\mathrm{CO}_{2}$ concentration at $\sim 370 \mu \mathrm{mol} \mathrm{mol}^{-1}$ (gain calibration). Both were from gas cylinders calibrated against a standard from the Meteorological Service of Canada, Downsview, ON, Canada. Halfhourly soil $\mathrm{CO}_{2}$ efflux $\left(F_{\mathrm{cs}}, \mu\right.$ mol $\left.\mathrm{CO}_{2} \mathrm{~m}^{-2} \mathrm{~s}^{-1}\right)$ was calculated using the following equation:

$$
F_{\mathrm{c}_{\mathrm{s}}}=\rho_{\mathrm{a}} \frac{V_{\mathrm{e}}}{A} \frac{d s_{\mathrm{c}}}{d t}
$$

where $\rho_{a}$ is the density of dry air in the chamber headspace $\left(\mathrm{mol} \mathrm{m}^{-3}\right), V_{\mathrm{e}}$ is the effective volume of the chamber $\left(\mathrm{m}^{3}\right)$, $A$ is the area of ground covered by the chamber $\left(\mathrm{m}^{2}\right)$, and $d s_{\mathrm{c}} / d t$ is the time rate of change of the $\mathrm{CO}_{2}$ mixing ratio in the chamber headspace over a 1-min interval following lid closure $\left(\mathrm{mol} \mathrm{CO}_{2} \mathrm{~mol}^{-1}\right.$ dry air s$\left.{ }^{-1}\right)$. The $V_{\mathrm{e}}$ value differs from the geometrical volume of the chambers because of moss porosity. It was measured daily using a gas injection technique described in detail by Drewitt et al. [2002] and by Gaumont-Guay et al. [2006].

[17] Compared with the control plots without root exclusion, heterotrophic respiration determined in plots with root exclusion was $40.6 \%$ of the total soil respiration. As root respiration was not only influenced by temperature but also by tree biological activities, they were excluded in this study. Most ecosystem models handle heterotrophic and root respiration separately, and therefore each of these components needs to be individually studied. Moss photosynthesis and respiration were removed from the measurements through taking the difference between control and root-exclusion plots in each pair assuming that moss photosynthesis and respiration were unaffected by the rootexclusion experiment [Gaumont-Guay et al., 2008]. In this way, the $\mathrm{CO}_{2}$ flux due to heterotrophic respiration only was obtained. Each flux value at a given time is the average of measurements of four plots. The hourly meteorological data are compiled from the data archive of Fluxnet-Canada website (http://fluxnet-canada.ccrp.ec.gc.ca/). These meteorological data were measured at the flux tower near chambers of heterotrophic respiration.

\subsection{Model Parameterization}

[18] The parameters used the integrated daily model (equation (16)) were ed at the site or determined through data fitting (see Table 2). Based on daily soil temperature at $2 \mathrm{~cm}$ depth, we found different values of $Q_{10}$ and $R_{10}$ in different months. The values of $Q_{10}$ are 4.0, 4.4 and 4.5 in July, August and September, respectively. The corresponding $R_{10}$ values are $1.66,1.77$ and $1.96 \mathrm{gC}$ $\mathrm{m}^{-2} \mathrm{~d}^{-1}$, respectively. Gaumont-Guay et al. [2006] showed that the $Q_{10}$ value for nighttime soil $\mathrm{CO}_{2}$ efflux during the growing season was 3.1 , and $R_{10}$ was 1.9 at the site. There may be several reasons for the $Q_{10}$ values derived from the chamber data to be considerably larger than the conventional value of 2.0: (1) the substrate active layer thickness increased with soil temperature, i.e., not only the microbial activity but also the total organic matter involved in respiration increased with temperature, causing a larger sensitivity to temperature than usually predicted with a constant substrate; (2) sensitivity to soil temperature is usually larger than that to air temperature [Kicklighter et al., 1994]; (3) the dynamic of soil temperature was relatively small in a month relative the natural variability in the measured $R_{h}$, causing errors in $Q_{10}$ determination; and (4) possible measurement errors using soil chambers based on nonsteady state methods [Pumpanen et al., 2004]. Gaumont-Guay et al. [2006] found a smaller value of $Q_{10}=3.1$ because it represents the whole growing season including May and June. It also indicates the possibility of larger errors in $Q_{10}$ determination over shorter periods (reason 3 above).

\section{Results}

\subsection{Sensitivity of Heterotrophic Respiration to Temperature at Different Soil Depths}

[19] To model the diurnal variation of heterotrophic respiration, we calculated the average daily air temperature and soil temperature using the half-hourly observed data. We also processed the observed half hourly heterotrophic respiration rates in each day to obtain the daily rate. Soil respiration from the root-exclusion treatment shows different temperature sensitivities at different soil depths. In this research, we use equation (1) and analyze the relationship between heterotrophic respiration and soil temperature at different soil depths using half-hourly measurements during the peak growing season. The results indicate that there are good exponential correlations between heterotrophic respiration and soil temperature at $2 \mathrm{~cm}$ and $5 \mathrm{~cm}$ soil depth, but at $10 \mathrm{~cm}$ depth the correlation is not significant (Table 3 and Figure 3).

[20] Based on half-hourly measurements of heterotrophic respiration and soil temperature at different soil depths, we 
Table 3. Exponential Fits Between Heterotrophic Respiration Obtained Through Root-Exclusion Experiments and Soil Temperature at Different Soil Depths With Half-Hourly Measurements During the Peak Growing Season ${ }^{\mathrm{a}}$

\begin{tabular}{lcc}
\hline $\begin{array}{c}\text { Soil Depth } \\
(\mathrm{cm})\end{array}$ & Fitted Equation & $R^{2}$ (Regression Coefficient) \\
\hline 2 & $R_{s}=0.6442 \exp \left(0.1025 T_{s}\right)$ & 0.681 \\
5 & $R_{s}=0.5566 \exp \left(0.1231 T_{s}\right)$ & 0.623 \\
10 & $R_{s}=0.6730 \exp \left(0.1132 T_{s}\right)$ & 0.221 \\
\hline
\end{tabular}

${ }^{\mathrm{a}} \mathrm{July}-$ September 2004. $R_{s}$ is soil respiration for root exclusion with halfhourly measurements $(\mu \mathrm{mol})$, and $T_{s}$ is soil temperature $\left({ }^{\circ} \mathrm{C}\right)$. Exponential fits from equation (1).

estimated monthly $Q_{10}$ values from regression analysis. As the soil temperature varied with depth while the total respiratory flux was the depth-integrated result, these values varied in a large range from 2.77 to 6.22 with depth from $2 \mathrm{~cm}$ to $10 \mathrm{~cm}$, in confirmation with previous studies [Gaumont-Guay et al., 2006]. At $2 \mathrm{~cm}$, these monthly $Q_{10}$ values vary from 4.0 and 4.5 in the July-September period, which are used in our final analysis. Equation (15) shows that the error in daily heterotrophic respiration estimation without considering the diurnal temperature variation is proportional to $\left(\ln Q_{10}\right)^{2}$, and it is therefore important to represent the seasonal variation in $Q_{10}$ in the integrated daily model.

\subsection{Heterotrophic Respiration Modeling Results}

[21] The soil temperature at $2 \mathrm{~cm}$ soil depth is used to model the heterotrophic respiration obtained from the rootexclusion experiment. The average daily soil temperature, the amplitude of the air temperature at $1 \mathrm{~m}$ above the surface, and average heterotrophic respiration are calculated from half-hourly measurements. The total daily heterotrophic respiration is simulated using models of equations (16) and (4), i.e., models with and without the consideration of the diurnal temperature variation. These two sets of modeled results are compared with measurements of daily heterotrophic respiration obtained as the summation of half hourly observations within the $24 \mathrm{~h}$ (Figure 4). In the comparison, the root mean square error (RMSE) was used as a criterion to evaluate the model performance (see Table 3), i.e.,

$$
R M S E=\sqrt{\frac{\sum_{i=1}^{n}\left(x_{i}-y_{i}\right)^{2}}{n}}
$$

where $x_{i}$ and $y_{i}$ are the modeled and measured values, respectively, and $n$ is the number of days. The values from the simple daily model have a relatively small slope in the regression between measured and modeled values and a relatively high value of $R M S E$ for monthly and growing season simulations (Table 4). Some of the scatter is due to irregular subdaily variations in weather conditions, especially in days when it was raining and had a large variation of temperature. The $R^{2}$ values are 0.78 and 0.79 for integrated and simple daily models, respectively.

\subsection{Effects of Diurnal Amplitude of Temperature on Heterotrophic Respiration}

[22] To show the importance of the diurnal amplitude of temperature on daily heterotrophic respiration estimation, we investigate the ratio $R_{h, \text { daily }} / R_{h}$ between uncorrected and corrected daily values as a function of the diurnal temperature amplitude at the soil surface (taken as that of the air temperature near the surface, Figure 5). $\tilde{R}_{h}$ is the daily total heterotrophic respiration using the simple daily respiration model after finding $Q_{10}$ and $R_{10}$ from the experimental data for each month, and $R_{h, \text { daily }}$ is estimated using the integrated daily model (equation (15)).

[23] This ratio indicates the extent of the bias error in the daily respiration model without considering the diurnal temperature variation. As mathematically described in equation (14), the effect of this amplitude on the diurnal variation of heterotrophic respiration increases with $\left(\ln Q_{10}\right)^{2}$ and the negative bias error is highly sensitive to the diurnal amplitude at the soil surface, increasing from about $10 \%$ at an amplitude of $10^{\circ} \mathrm{C}$ to about $38 \%$ at an amplitude of $20^{\circ} \mathrm{C}$ when $k=0$ and $Q_{10}=4.0$. The actual values of $R_{h \text {,daily }} /$ $\tilde{R}_{h}$ found from the experimental data sets are also shown in Figure 5. The diurnal amplitude at the experimental site at the high latitude is generally small $\left(2-12^{\circ} \mathrm{C}\right.$ with a mean of $7.0^{\circ} \mathrm{C}$ ), and the maximum bias error (underestimation) in the daily heterotrophic respiration estimation is less than $15 \%$, with a mean of $4.5 \%$. This error may appear to be small, but it is highly significant as $4.5 \%$ of the global heterotrophic respiration of $68-76.5 \mathrm{Pg} \mathrm{Cy}^{-1}$ [Raich and Schlesinger, 1992] is larger than the current terrestrial carbon sink [Canadell et al., 2007]. However, compared with the temporal scaling of daily photosynthesis [Chen et al., 1999], this nonlinear effect on respiration scaling is considerably smaller. Although field measurements of heterotrophic respiration generally have errors much larger than the scaling error found in our study, the scaling methodology can still be used to achieve a large improvement in regional and global terrestrial carbon cycle modeling, which usually depends on the functional form of

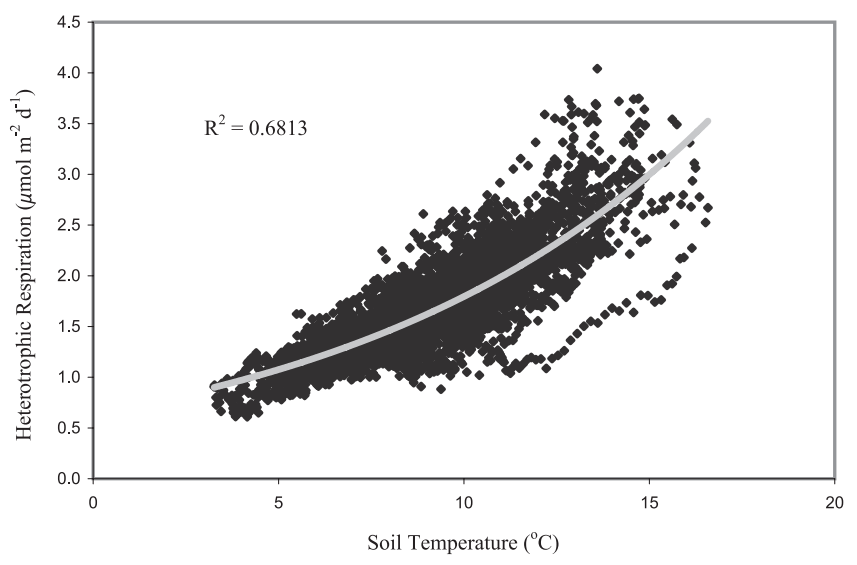

Figure 3. Relationship between heterotrophic respiration and soil temperature at $2 \mathrm{~cm}$ soil depth with half-hourly measurement data during the peak growing season (JulySeptember 2004). 


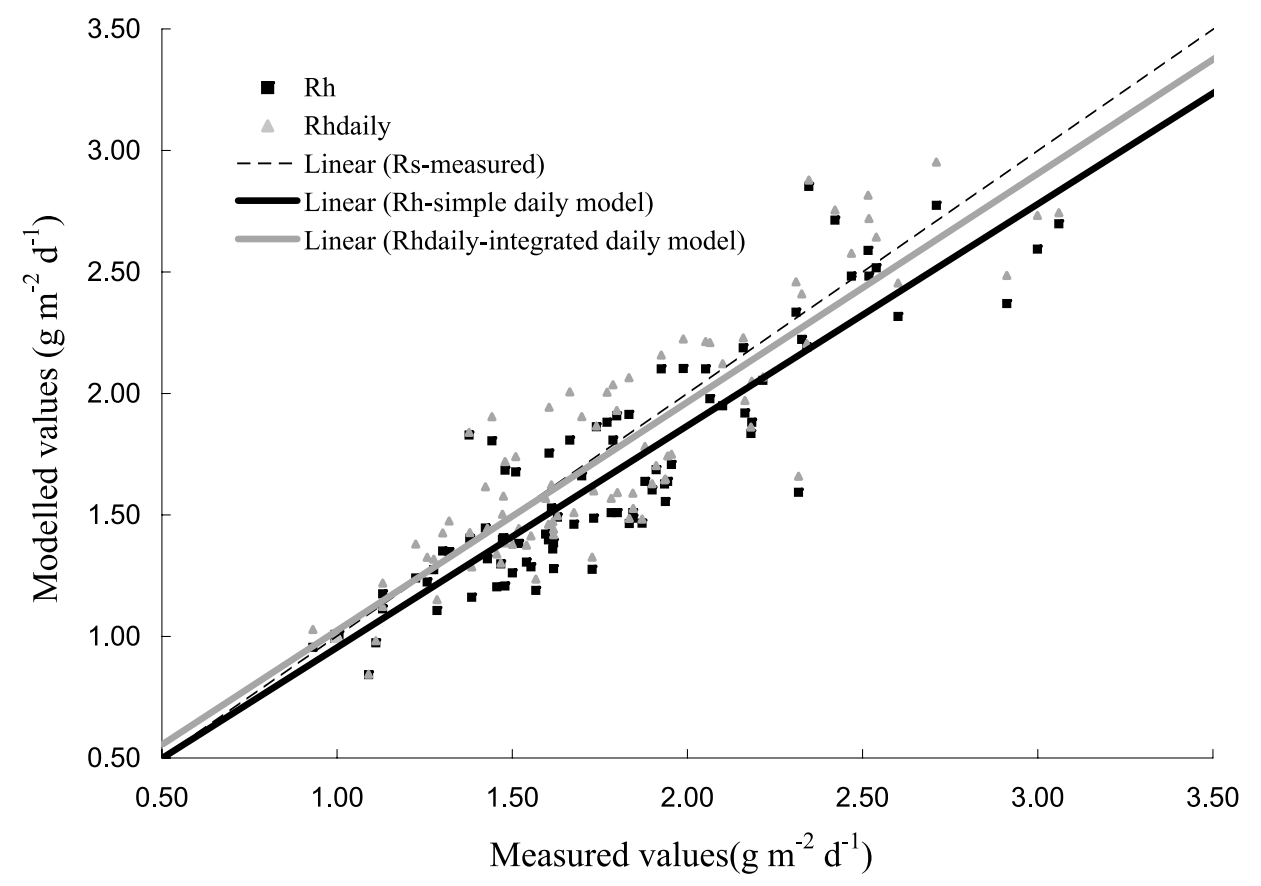

Figure 4. The comparison of modeled and measured daily heterotrophic respiration during the growing season for the root-exclusion treatment at the Black Spruce site.

respiration derived from measurements while their absolute values are adjusted through spin-up procedures.

\section{Discussion}

\subsection{Influences of $Q_{10}$ and the Vertical Decay Rate $(k)$} of Soil Carbon

[24] The integrated daily model (equation (15)) demonstrates a general relationship between $R_{h, \text { daily }}$ and diurnal temperature amplitude $(A)$ at different values of $k$ and $Q_{10}$. Based on the integrated daily model, Figure 6 demonstrates that this error is also sensitive to the $k$ value, increasing from $38 \%$ at $k=0\left(\mathrm{~cm}^{-1}\right)$ to $44 \%$ at $k=0.03\left(\mathrm{~cm}^{-1}\right)$ at $A=20^{\circ} \mathrm{C}$ and $Q_{10}=4$, or from $10 \%$ at $k=0\left(\mathrm{~cm}^{-1}\right)$ to $11 \%$ at $k=0.03$ $\left(\mathrm{cm}^{-1}\right)$ at $A=20^{\circ} \mathrm{C}$ and $Q_{10}=2$. The mathematical form of this sensitivity with $k$ is exponential as shown in equation (15). Physically, this sensitivity is caused by the fact that the diurnal temperature amplitude decreases exponentially with depth. With a damping depth of $6 \mathrm{~cm}$, the amplitude can decrease from $10^{\circ} \mathrm{C}$ at the surface to $4.3^{\circ} \mathrm{C}$ at $5 \mathrm{~cm}$ and to $0.8^{\circ} \mathrm{C}$ at $15 \mathrm{~cm}$. The vertical distribution of soil carbon is therefore also important in the temporal scaling of the heterotrophic respiration. Based on Grant et al. [2005] who provided soil organic carbon contents at various depths at two sites, the Old Aspen and the Old Jack Pine of BOREAS, we estimated the $k$ values to be 0.0215 and $0.0415 \mathrm{~cm}^{-1}$ at these two sites, respectively. These nonzero $k$ values suggest that the error in the simple daily respiration estimation (equation (1)) could be significantly larger at these two sites. This sensitivity of daily respiration estimation to the soil carbon profile suggests that considering the vertical distribution of organic carbon in soil can significantly improve of our current daily, monthly and annual respiration models of heterotrophic respiration.

\subsection{Influences of Multiple Soil Layers With Different Vertical Decay Rates}

[25] The experimental data used in this study were obtained from a forest stand with a thick organic layer $(15-30 \mathrm{~cm})$ on top of the mineral soil. As most carbon in the soil is located in this organic layer which have a fairly uniform carbon density, the simple treatment of $k=0$ was a good approximation. The multilayer model (equation (18)) can be used to assess the error due to ignoring the vertical carbon distribution pattern in the mineral soil. Assuming the organic layer has a thickness of $15 \mathrm{~cm}$ with weight $w_{1}=0.8$ and decay rate $k=0 \mathrm{~cm}^{-1}$ and the mineral soil has a thickness of $50 \mathrm{~cm}$ with $w_{2}=0.2$ and $k=0.03 \mathrm{~cm}^{-1}$, it is found from equation (18) that the $R_{h \text {,daily }} / \tilde{R}_{h}$ ratio at a diurnal air temperature amplitude of $10^{\circ} \mathrm{C}$ would be 1.077 , which is about $2 \%$ less than the value of 1.095 with the simple treatment of $k=0$ for the organic layer only. Under this two-layer treatment, the ratio is reduced because of the contribution of the deeper layer with smaller diurnal temperature variation to the total heterotrophic respiration.

[26] In ecosystems with a moderate organic/litter layer and a carbon-rich mineral soil layer, a similar two-layer treatment can be made to equation (18). If we assume that

Table 4. Root Mean Square Errors of the Modeling Results in Different Months in 2004 at the Old Black Spruce Site ${ }^{a}$

\begin{tabular}{lccccccc}
\hline & \multicolumn{3}{c}{ Integrated Daily } & Model & & \multicolumn{3}{c}{ Simple Daily Model } \\
\cline { 2 - 4 } \cline { 6 - 8 } \multicolumn{1}{c}{ Month } & Slope & Intercept & RMSE & & Slope & Intercept & RMSE \\
\hline Jul. & 0.9235 & 0.1554 & 0.2685 & & 0.9092 & 0.0683 & 0.2770 \\
Aug. & 0.8710 & 0.2533 & 0.2541 & & 0.8504 & 0.1544 & 0.2606 \\
Sep. & 0.8649 & 0.1560 & 0.1669 & & 0.8784 & 0.0738 & 0.1934 \\
Growing season & 0.9319 & 0.0906 & 0.2281 & & 0.9124 & 0.0419 & 0.2418 \\
\hline
\end{tabular}

${ }^{\mathrm{a}} \mathrm{RMSE}$, root mean square errors. 


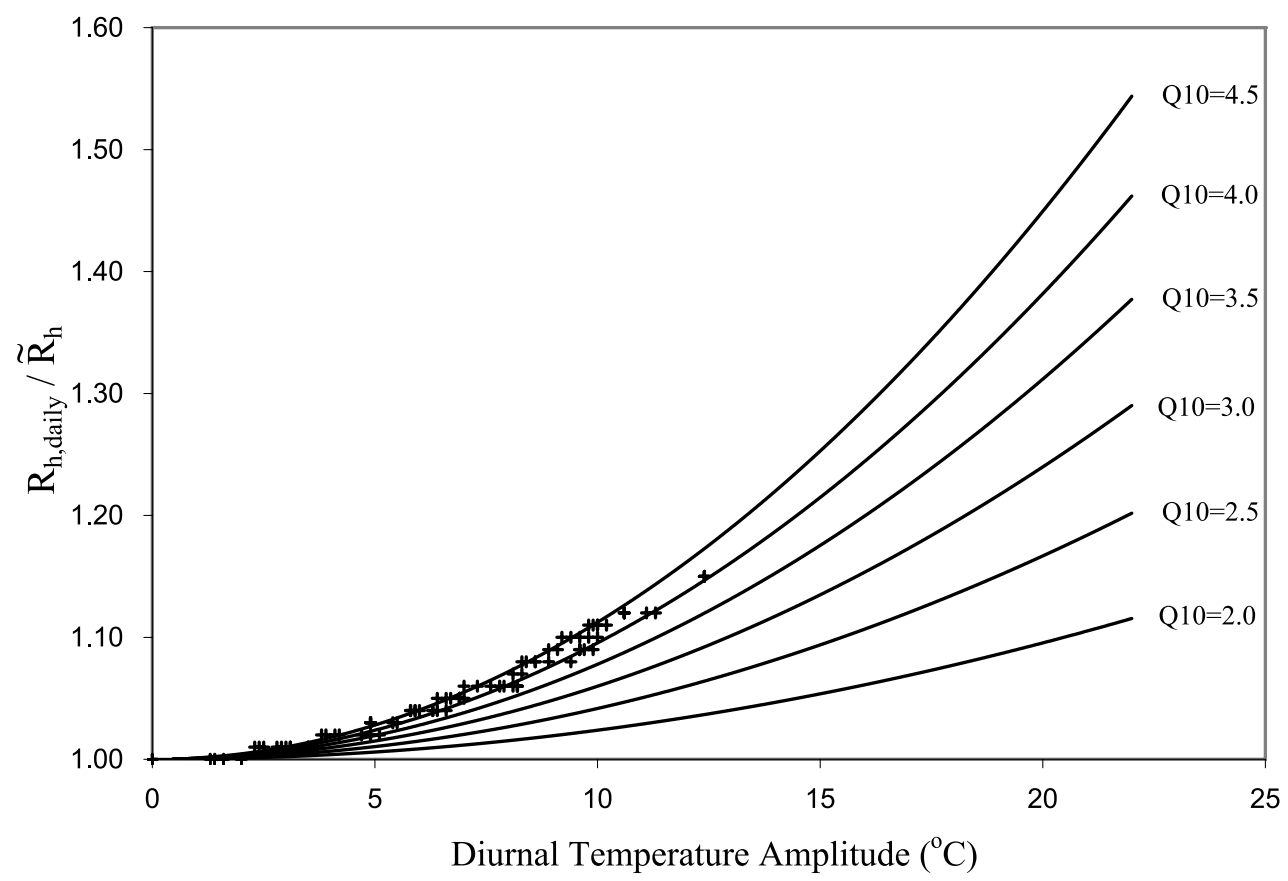

Figure 5. The relationship between the ratio $R_{h, \text { daily }} / \tilde{R}_{h}$ and temperature amplitude at different $Q_{10}$ values when the decay rate $(k)$ of organic $\mathrm{C}$ content with depth is zero. The pluses indicate the actual values of $R_{h, \text { daily }} / \tilde{R}_{h}$ calculated using $Q_{10}$ and $R_{10}$ found from the experimental data for each month at $k=$ 0 . The temperature amplitude is for air $1 \mathrm{~m}$ above ground.

the organic layer has a thickness of $5 \mathrm{~cm}$ with $k=0$ and $w_{1}=$ 0.2 and that the carbon-containing soil mineral layer has a thickness of $30 \mathrm{~cm}$ with $k=0.03$ and $w_{2}=0.8$, the $R_{h \text {,daily }} /$ $\tilde{R}_{h}$ ratio at a diurnal air temperature amplitude of $10^{\circ} \mathrm{C}$ and $Q_{10}=2.0$ would be 1.058 . If the organic layer is removed, i.e., the mineral soil has a thickness of $30 \mathrm{~cm}$ with $k=0.03$ and $w_{1}=1.0$, the ratio is increased to 1.067 . This is because without the thermal damping effect the diurnal temperature amplitude in the mineral soil would increase. The difference in $k$ between the two layers causes less than $1 \%$ difference

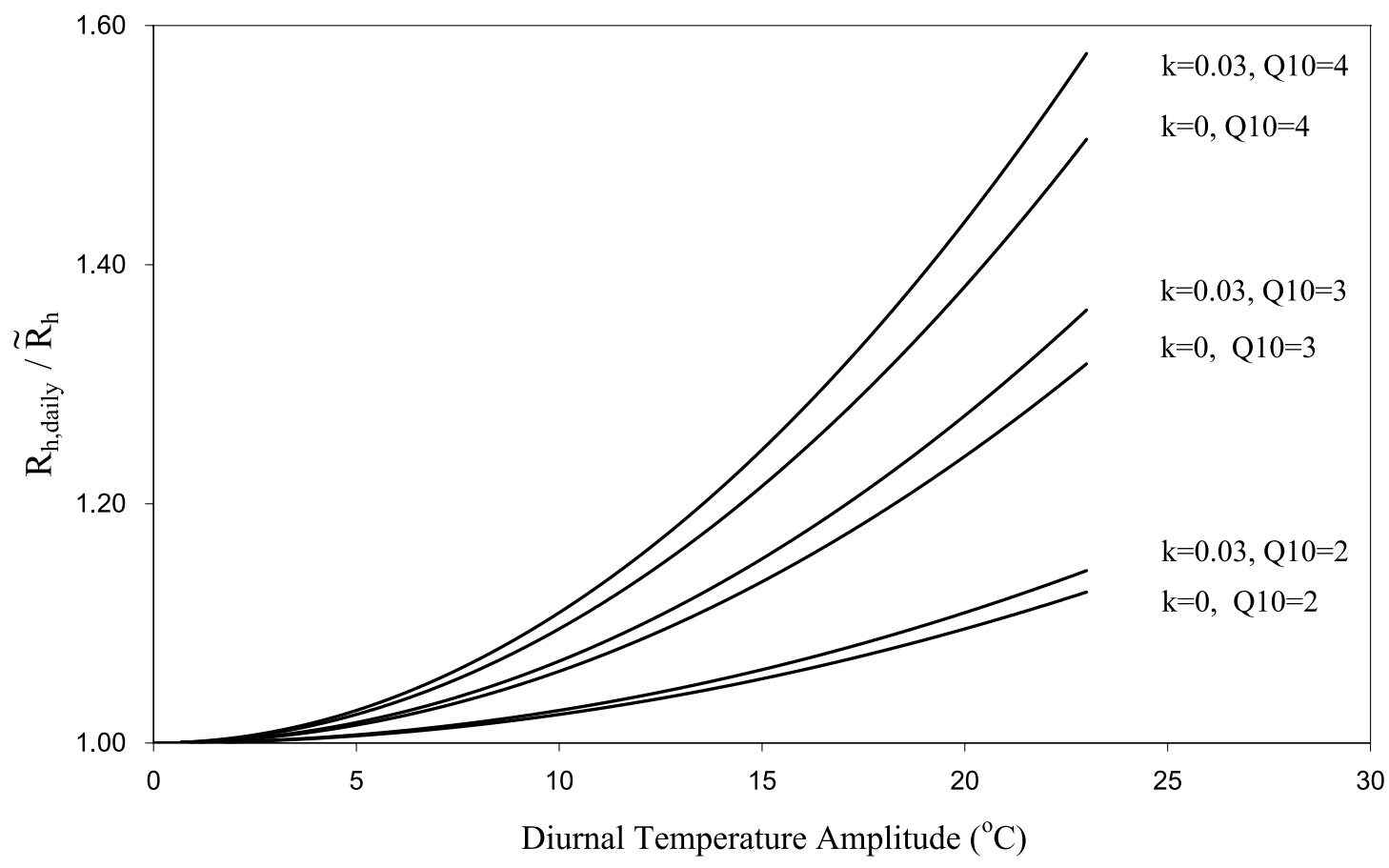

Figure 6. The relationship between the ratio $R_{h, \text { daily }} / \tilde{R}_{h}$ and temperature amplitude at different decay rates $\left(k, \mathrm{~cm}^{-1} \quad\right.$ ganic C content with depth for $Q_{10}=2.0, Q_{10}=3.0$, and $Q_{10}=4.0$. 
in the ratio. It is also noted from Figure 6 that the nonlinear correction, i.e., the $R_{h \text {,daily }} / \tilde{R}_{h}$ ratio, is more sensitive to $Q_{10}$ and than to $k$ within a realistic range. This implies that for general purposes, a 1-layer model with a constant $k$ value would be useful for the first order correction of this nonlinear effect. The error caused by the $k$ variation with depth would generally be less than $2-3 \%$ of the total heterotrophic respiration.

\subsection{Influences of Litter Quality and Soil Moisture}

[27] In our study, we have only considered the vertical distribution of the total soil carbon without paying specific attention to the quality of the litter and organic matter. In general, soil carbon becomes more recalcitrant (longer turnover time) in deeper layers [Trumbore et al., 1996]. The influence of this carbon quality variation with depth can increase the nonlinear effect, and this increased effect can be effectively considered by either decreasing the effective carbon-containing soil depth (i.e., $z_{d}$ in equations (15) or (16)) or increasing the $k$ value, to allow the more labile carbon closer to the soil surface more exposed to diurnal temperature variation. In our current study, we found the best fit with experimental data when the lower bound value of $z_{d}=15 \mathrm{~cm}$ (Table 2) was used, and this may be due to the litter quality variation with depth.

[28] Soil moisture not only affects the total heterotrophic respiration but also the thermal diffusivity that influences the thermal damping depth used in the model. While the influence on the total heterotrophic respiration does not change the relative $R_{h \text {,daily }} / \tilde{R}_{h}$ ratio, the influence on the damping depth can cause a considerable error in the ratio. In the example of one layer soil with a thickness of $30 \mathrm{~cm}$ and $k=0.03$, an increase of the damping depth $D$ from $6 \mathrm{~cm}$ to $8 \mathrm{~cm}$ would cause the ratio to increase from 1.067 to 1.087 because a larger damping depth would allow the diurnal thermal wave to penetrate deeper into the soil, causing a larger nonlinear effect on respiration. Soil moisture influences the damping depth in a complex way. In dry soils, $D$ increases with moisture, but in wet soils, it may decrease with moisture as soil water may increase the thermal capacity more than the thermal conductivity [Monteith and Unsworth, 1990]. The value of $D$ for organic matter is quite different from that for mineral soils [Monteith and Unsworth, 1990]. We therefore suggest that different values of $D$ be assigned to different soil layers when the multilayer model (equation (18)) is used.

\section{Conclusions}

[29] An analytically integrated daily heterotrophic respiration model is developed for the purpose of its temporal scaling in daily ecological models. The scaling model is tested using field data in a mature black spruce stand in Canada. Based on the present study, the following conclusions are drawn:

[30] 1. With detailed half-hourly measurements of heterotrophic respiration through root exclusion experiments, we are able for the first time to test the analytical daily model. The model is simple and is shown to be capable of capturing the first order effects of diurnal temperature variability on heterotrophic respiration estimation at daily time steps (as shown in equation (4) and Figure 5).
[31] 2. The effect of the diurnal temperature amplitude on heterotrophic respiration estimation at daily steps increases with the $Q_{10}$ value, and the negative bias error in the daily respiration estimation without considering the diurnal temperature variation is highly sensitive to this amplitude, increasing from about $10 \%$ at an amplitude of $10^{\circ} \mathrm{C}$ to about $38 \%$ at an amplitude of $20^{\circ} \mathrm{C}$ when the vertical distribution of soil carbon is uniform.

[32] 3. The diurnal temperature amplitude at the experimental site at the high latitude was small $\left(2-12^{\circ} \mathrm{C}\right.$, with a mean of $7.0^{\circ} \mathrm{C}$ ), and the largest negative bias error by ignoring the temperature variation in the daily heterotrophic respiration estimation was less than $15 \%$, with a mean value of $4.5 \%$.

[33] 4. Based on the temporal scaling model, the negative bias error in daily respiration estimation using the daily mean temperature is also somewhat sensitive to the vertical distribution of the soil carbon, the thermal diffusivity affecting the thermal damping depth, and the effective soil carbon-containing depth. A complete multilayer model is also developed to evaluate the effects on these parameters on daily heterotrophic respiration estimation.

[34] Acknowledgments. This research was part of the Fluxnet Canada Research Network supported by the Canadian Foundation for Climate and Atmospheric Sciences, the Natural Science and Engineering Council of Canada, and BIOCAP Canada. S. E. Huang thanks Jiangxi Province of People's Republic of China for providing a visiting fellowship to the University of Toronto.

\section{References}

Aber, J. D., and C. A. Federer (1992), A generalized, lumped-parameter model of photosynthesis, evapotranspiration and net primary production in temperate and boreal forest ecosystems, Oecologia, 92, 463-474.

Arrhenius, S. (1889), Uber die Reaktionsgeschwindigkeit bei der Inversion von Rohrzucker durch Sauren, Z. Phys. Chem., 4, 226-248.

Braswell, B. H., W. J. Sacks, E. Linder, and D. S. Schimel (2005), Estimating diurnal to annual ecosystem parameters by synthesis of a carbon flux model with eddy covariance net ecosystem exchange observations, Global Change Biol., 11, 335-355.

Canadell, J. G., C. Le Quéré, M. R. Raupach, C. B. Field, E. T. Buitehuis, P. Ciais, T. J. Conway, N. P. Gillett, R. A. Houghton, and G. Marland (2007), Contributions to accelerating atmospheric $\mathrm{CO}_{2}$ growth from economic activity, carbon intensity, and efficiency of natural sinks, Proc. Natl. Acad. Sci. U. S. A., 104(47), 18,866-18,870.

Chen, J. M., J. Liu, J. Cihlar, and M. L. Guolden (1999), Daily canopy photosynthesis model through temporal and spatial scaling for remote sensing applications, Ecol. Modell., 124, 99-119.

Chen, J. M., et al. (2003), Spatial distribution of carbon sources and sinks in Canada's forests, Tellus, Ser. B, 55, 622-641.

Cramer, W., et al. (1999), Comparing global models of terrestrial net primary productivity (NPP): Overview and key results, Global Change Biol., 5, suppl., 1-15.

Davidson, E. A., E. Belk, and R. D. Boone (1998), Soil water content and temperature as independent or confounded factors controlling soil respiration in a temperate mixed hardwood forest, Global Change Biol., 4, 217-227.

Davidson, E. A., S. E. Trumbore, and R. Amundson (2000), Soil warming and organic carbon content, Nature, 408, 789-790.

Drewitt, G. B., T. A. Black, Z. Nesic, E. R. Humphreys, E. M. Jork, R. Swanson, G. J. Ethier, T. Griffis, and K. Morgenstern (2002), Measuring forest-floor $\mathrm{CO}_{2}$ fluxes in a Douglas-fir forest, Agric. For. Meteorol., $110,299-317$.

Gaumont-Guay, D., T. A. Black, T. J. Griffis, A. G. Barr, R. S. Jassal, and Z. Nesic (2006), Interpreting the dependence of soil respiration on soil temperature and water content in a boreal aspen stand, Agric. For. Meteorol., 140, 220-235.

Gaumont-Guay, D., et al. (2008), Biophysical controls on rhizospheric and heterotrophic components of soil respiration in a boreal black spruce stand, Tree Physiol., 28, 161-171.

Grant, R. F., P. G. Jarvis, J. M. Massheder, S. E. Hale, and J. B. Moncrieff (2001), Control on carbon and energy exchange by a black spruce-moss 
ecosystem: Testing the mathematical model ecosys with data from the BOREAS experiment, Global Biogeochem. Cycles, 15, 129-147.

Grant, R. F., A. Arain, V. Arora, A. Barr, T. A. Black, J. M. Chen, S. Wang, F. Yuan, and Y. Zhang (2005), Modelling high temperature effects on $\mathrm{CO}_{2}$ and energy exchange in temperate and boreal coniferous forests, Ecol. Modell., 188, 217-252.

Gulledge, J., and J. P. Schimel (2000), Controls on soil carbon dioxide and methane fluxes in a variety of Taiga forest stands in interior Alaska, Ecosystems (N. Y., Print), 3, 269-282.

Hall, F. G., A. K. Betts, S. Frolking, R. Brown, J. M. Chen, W. Chen, S. Halldin, D. Lettenmaier, and J. Schafer (2004), The boreal climate, in Vegetation, Water, Humans and the Climate: A New Perspective on an Interactive System, edited by P. Kabat et al., pp. 93-114, Springer, New York.

Irvine, J., and B. E. Law (2002), Contrasting soil respiration in young and old - growth ponderosa pine forests, Global Change Biol., 8, 1183 1194.

Janssens, I. A., and K. Pilegaard (2003), Large seasonal changes in $Q_{10}$ of soil respiration in a beech forest, Global Change Biol., 9, 911-918.

Janssens, I. A., et al. (2003), Climatic influences on seasonal and spatial differences in soil $\mathrm{CO}_{2}$ efflux, in Canopy Fluxes of Energy, Water and Carbon Dioxide of European Forests, pp. 235-256, Springer, Berlin.

Jobbagy, E. G., and R. B. Jackson (2000), The vertical distribution of soil organic carbon and its relation to climate and vegetation, Ecol. Appl. $10(2), 423-436$

Johansson, G. (1992), Release of organic C from growing roots of meadow fescue (Festuca pratensis L.), Soil Biol. Biochem., 24, 427-433.

Kalyn, A. L., and K. C. J. Van Rees (2006), Contribution of fine roots to ecosystem biomass and net primary production in black spruce, aspen and jack pine forests in Saskatchewan, Agric. For. Meteorol., 140, $236-$ 243.

Kicklighter, D. W., et al. (1994), Aspects of spatial and temporal aggregation in estimating regional carbon dioxide fluxes from temperate forest soils, J. Geophys. Res., 99, 1303-1315.

Lee, M. S., K. Nakane, T. Nakatsubo, W. H. Mo, and H. Koizumi (2002), Effects of rainfall events on soil $\mathrm{CO}_{2}$ flux in a cool temperate deciduous broad-leaved forest, Ecol. Res., 17, 401-409.

Lee, M. S., K. Nakane, T. Nakatsubo, and H. Koizumi (2003), Seasonal changes in the contribution of root respiration to total soil respiration in a cool-temperate deciduous forest, Plant Soil, 255, 311-318.

Lloyd, J., and J. A. Taylor (1994), On the temperature dependence of soil respiration, Funct. Ecol., 8, 315-323.

Luo, Y., et al. (2001), Acclimatization of soil respiration to warming in a tall grass prairie, Nature, 413, 622-625.

Melillo, J. M., et al. (1993), Global climate change and terrestrial net primary production, Nature, 363, 234-240

Monteith, J. L., and M. H. Unsworth (1990), Transient heat balance, in Principles of Environmental Physics, pp. 218-230, Elsevier, New York.

Parton, W. J., and J. M. Scurlock (1993), Obervation and modeling of biomass and soil organic matter dynamics for the Grassland biome worldwide, Global Biogeochem. Cycles, 7, 785-809.

Parton, W. J., D. S. Schimel, C. V. Cole, and D. S. Ojima (1987), Analysis of factors controlling soil organic matter levels in Great Plains grasslands, Soil Sci., 51, 1173-1179.

Peng, C. H., M. J. Apps, and D. T. Price (1998), Simulation carbon dynamics along the Boreal Forest Transect Case Study (BFTCS) in central Canada, Global Biogeochem. Cycles, 12, 381-392.
Pumpanen, J., et al. (2004), Comparison of different chamber techniques for measuring soil $\mathrm{CO}_{2}$ efflux, Agric. For. Meteorol., 123, 159-176.

Qi, Y., M. Xu, and J. Wu (2002), Temperature sensitivity of soil respiration and its effects on ecosystem carbon budget: Nonlinearity begets surprises, Ecol. Modell., 153, 131-142.

Raich, J. W., and C. S. Potter (1995), Global patterns of carbon dioxide emissions from soils, Global Biogeochem. Cycles, 9, 2336.

Raich, J. W., and W. H. Schlesinger (1992), The global carbon dioxide flux in soil respiration and its relationship to vegetation and climate, Tellus, Ser $B, 44,8199$.

Rayment, M. B., and P. G. Jarvis (2000), Temporal and spatial variation of soil $\mathrm{CO}_{2}$ efflux in a Canadian boreal forest, Soil Biol. Biochem., 32, 3545

Rodeghiero, M., and A. Cescatti (2005), Main determinants of forest soil respiration along an elevation/temperature gradient in the Italian Alps, Global Change Biol., 11, 1024-1041.

Russell, C. A., and R. P. Voroney (1998), Carbon dioxide efflux from the floor of a boreal aspen forest. I. Relationship to environmental variables and estimates of C respired, Can. J. Soil Sci., 78, 301-310.

Ryan, M. G. (1991), Effects of climate change on plant respiration, Ecol. Appl., 1, 157-167.

Schimel, D. S. (1995), Terrestrial ecosystems and the carbon-cycle, Global Change Biol., 1, 7791.

Schimel, D. S., et al. (1997), Continental scale variability in ecosystem processes: Models, data, and the role of disturbance, Ecol. Monogr., $67,251-271$

Thierron, V., and H. Laudelout (1996), Contribution of root respiration to total $\mathrm{CO}_{2}$ efflux from the soil of a deciduous forest, Can. J. For. Res., 26, $1142-1148$

Tjoelker, M. G., J. Oleksyn, P. B. Reich, and R. Zytkowiak (2008), Coupling of respiration, nitrogen, and sugars underlies convergent temperature acclimation in Pinus banksiana across wide-ranging sites and populations, Global Change Biol., 14, 782-797.

Trumbore, S. E., O. A. Chadwick, and R. Amundson (1996), Rapid exchange of soil carbon and atmospheric $\mathrm{CO}_{2}$ driven by temperature change, Science, 272, 393-396.

Van't Hoff, J. H. (1898), Chemical Dynamics, vol. 1, translated by R. A. Lehfeldt, pp. 224-229, Edward Arnold, London.

Wythers, K. R., P. B. Reich, M. G. Tjoelker, and P. B. Bolstad (2005), Foliar respiration acclimation to temperature and temperature variable Q10 alter ecosystem carbon balance, Global Change Biol., 11, 435-448.

$\mathrm{Xu}$, M., and Y. Qi (2001a), Soil surface $\mathrm{CO}_{2}$ efflux and its spatial and temporal variation in a young ponderosa pine plantation in California, Global Change Biol., 7, 667-677.

$\mathrm{Xu}, \mathrm{M}$., and Y. Qi (2001b), Spatial and seasonal variations of $Q_{10}$ determined by soil respiration measurements at a Sierra Nevadan forest, Global Biogeochem. Cycles, 15, 687-696.

T. A. Black and D. Gaumont-Guay, Faculty of Agricultural Science, University of British Columbia, Vancouver, BC V6T 1Z4, Canada.

J. M. Chen and W. Ju, Department of Geography, University of Toronto, 100 St. George Street, Room 5047, Toronto, ON L4Z 3Y7, Canada. (chenj@geog.utoronto.ca)

S. E. Huang, Meteorological Research Institute of Jiangxi Province, 330046 Nanchang, China. (huangshue99@hotmail.com) 